\title{
Nuclear Morphological Changes in Papillary Thyroid Carcinoma Cell: The Utility of a 3-Dimensional (3D) Holographic Microscopy in Cytology
}

\section{Shoko Kure ${ }^{* 1,2}$, Mitsuhiro Kudo ${ }^{1}$, Kousuke Ishino ${ }^{1}$, Ryuichi Wada ${ }^{1,2}$ and Zenya Naito ${ }^{1,2}$}

${ }^{1}$ Department of Integrated Diagnostic Pathology, Nippon Medical School, Tokyo, Japan

${ }^{2}$ Department of Pathology, Nippon Medical School Hospital, Tokyo, Japan

*Corresponding author: Shoko Kure, Department of Integrated Diagnostic Pathology, Nippon Medical School, Tokyo, Japan, Tel: +81-3-3822-2131; E-mail: skure@nms.ac.jp

Received date: December 05, 2018; Accepted date: December 12, 2018; Published date: December 18, 2018

Copyright: (c) 2018 Kure S, et al. This is an open-access article distributed under the terms of the Creative Commons Attribution License, which permits unrestricted use, distribution, and reproduction in any medium, provided the original author and source are credited.

\section{Image Article}

Fine needle aspiration cytology (FNAC) is an essential method to diagnose thyroid nodules. To diagnose papillary thyroid carcinoma (Figure 1a), distinct nuclear morphological changes such as nuclear groove (Figure 1b) and pseudo-nuclear inclusion (Figure 1c) are crucial features. At times, findings by FNAC with conventional cytology and findings by liquid-based cytology method are ambiguous. Subsequently, re-biopsy or even diagnostic resection is required. Additional or alternative methods to FNAC would be advantageous in diagnosing thyroid nodules.

Optical diffraction tomography (ODT) microscopy (HT-2H, Tomocube Inc., Daejeon, Korea) is a 3D-holographic microscope to scan cells in three dimensions. This microscope has $110 \mathrm{~nm}$ lateral and $356 \mathrm{~nm}$ axial optical resolution. Image reconstruction is performed according to the reflection index and the thickness of the samples, which provides morphological information. Using the objective lenses with a magnification of $60 x$, nuclear, nucleoli, and lipid droplets, and other cytoplasmic organelles can be observed, similar to confocal laser microscopy. KTC-1 is a human papillary thyroid carcinoma cell-line, established from the malignant pleural effusion of a recurrent thyroid carcinoma patient. Detection of morphological changes of nuclear of KTC-1 cells by the phase-contrast microscope is not possible by conventional monolayer culture. Hence, formalin-fixed KTC-1 cells were stained with 4',6-diamidino-2-phenylindole (DAPI) and observed by $\mathrm{HT}-2 \mathrm{H}$.

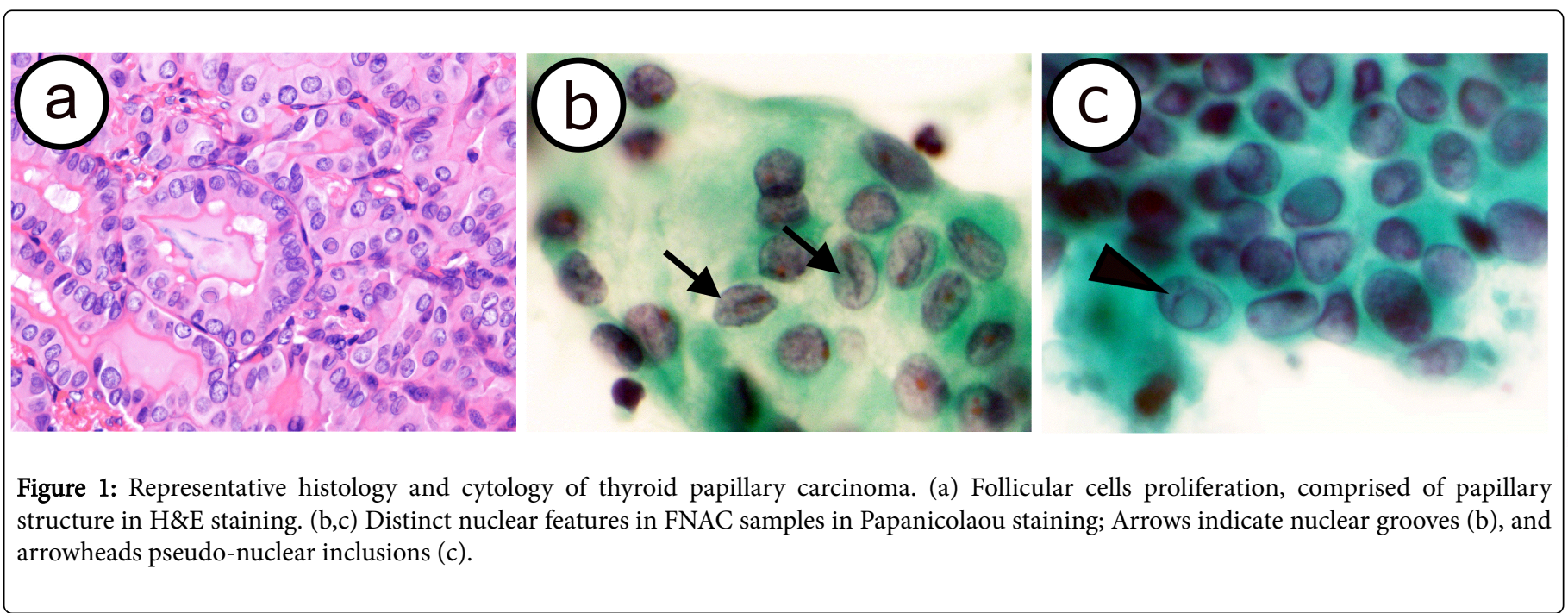

The hollow, irregular nuclear shapes of KTC-1 cells were clearly detected (Figure 2). These shapes indicate a nuclear groove and pseudo nuclear inclusion. Thus, observation and detection of nuclear morphological changes using whole cell images of FNAC nodule samples in 3D may be possible. ODT successfully captured nuclear morphological changes. Use of 3D-holographic microscopes may provide an alternative method or provide additional information for thyroid nodule diagnosis in cytology. 
Citation: Kure S, Kudo M, Ishino K, Wada R, Naito Z (2018) Nuclear Morphological Changes in Papillary Thyroid Carcinoma Cell: The Utility of a 3-Dimensional (3D) Holographic Microscopy in Cytology. J Cytol Histol 9: 527. doi:10.4172/2157-7099.1000527

Page 2 of 2

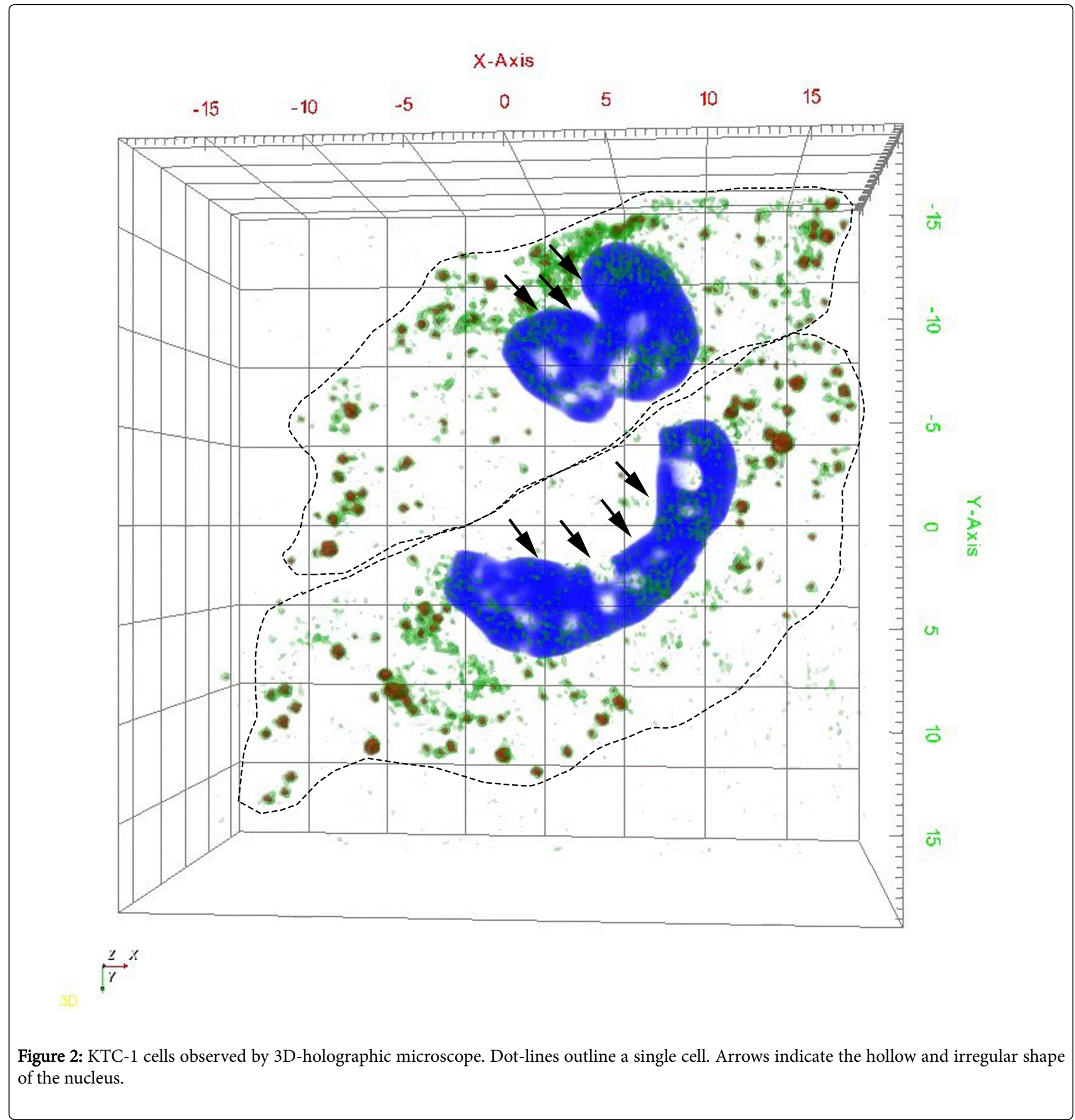

\section{Acknowledgement}

This work is supported by the Japanese Association of University Women and Children's Cancer Association of Japan. The authors thank Dr. Norisato Mitsutake, Nagasaki University, for providing KTC-1 cell- lines, and LMS Co., Ltd. Scientific Instruments Div., Kiyoko Kawahara, Takenori Fujii, Kiyoshi Teduka, Yoko Kawamoto and Taeko Kitamura for their skillful assistance. 